\title{
Digital Journalism
}

\section{DIBITAL}

JOURNGLISM

\section{Unmanned Aerial Vehicles and Journalistic Disruption}

\section{Valerie Belair-Gagnon, Taylor Owen \& Avery E. Holton}

To cite this article: Valerie Belair-Gagnon, Taylor Owen \& Avery E. Holton (2017):

Unmanned Aerial Vehicles and Journalistic Disruption, Digital Journalism, DOI:

10.1080/21670811.2017.1279019

To link to this article: http://dx.doi.org/10.1080/21670811.2017.1279019

$$
\text { 曲 Published online: } 27 \text { Jan } 2017 .
$$

Submit your article to this journal

LII Article views: 111

Q View related articles $₫$

View Crossmark data $\nearrow$ 


\title{
UNMANNED AERIAL VEHICLES AND JOURNALISTIC DISRUPTION Perspectives of early professional adopters
}

\author{
Valerie Belair-Gagnon ${ }^{\circledR}$, Taylor Owen and Avery E. Holton
}

\begin{abstract}
In recent years, there has been a surge in research on small unmanned aerial vehicles (UAVS) in news production and news audience engagement. Most of this research has focused on legal, ethical, and regulatory implications of UAVs in newsgathering, while paying less attention to the journalists' perspectives. To fill this gap in the academic literature, this article explores the ethical principles that guide journalists who use UAVs, how they have worked within these ethical principles, and how they can serve as disruptive innovators. Semistructured interviews with 13 UAV early adopters reveal that legal and regulatory restraints on UAVs facilitated the emergence of a new form of norm entrepreneur inside journalistic institutions. These individuals were able to experiment on the fringes of acceptable practice. In so doing, they seeded their organizations with the skill set and institutional capacity to engage constructively with the use of UAVs once constraints were lifted.
\end{abstract}

KEYWORDS disruptive innovation; drones; early adopters; innovation; journalism; news production; news gathering; unmanned aerial vehicles

\section{Introduction}

Recent research has examined journalistic unmanned aerial vehicle (UAV) (or drone) use from a multitude of theoretical and practical perspectives, focusing primarily on legal, ethical, and regulatory implications (Calo 2011; Chapa 2013; Clarke 2014; Culver 2014; Finn and Wright 2012; Kaminski 2013; Tremayne and Clark 2014; Waite 2014). Journalistic voices have been mostly absent from this body of work. This paper attempts to fill this gap in the academic literature by interviewing a set of US journalists who experimented with drones within a period of fluid regulatory, ethical, and normative context space. We explore what these early disruptive innovators can teach us about the broader incorporation of new technologies into the practice of journalism. The findings of this paper apply primarily to the US legal framework. Given that in the last two years the laws and regulations that guide users of UAVs have been fluid, journalists are experimenting with the technology differently in other countries.

In June 2016, the Federal Aviation Administration (FAA) announced long-awaited amendments to federal aviation regulations governing the use of small commercial (as opposed to hobbyist) unmanned aerial systems. As drone journalism scholar Matt Waite (2016a) summarized, these changes have had implications for how citizens and 
newsrooms alike can use UAVs. Users must be at least 16 years old, be able to understand the English language, and have an operator's certificate, which involves taking a rigorous knowledge test. With this certificate, UAV users are able to fly small UAVs up to 400 feet above the ground and fly over people around restricted airspaces.

The new FAA regulations have formalized what has been a period of unstructured experimentation with drones in American journalism. As the use of UAVs institutionalizes inside American newsrooms, it is important to reflect on how US journalists used UAVs in the period preceding the current fluid ethical and regulatory norms. This research examines this period of experimentation, outside the bounds of established journalistic practice. This article focuses on how a small network of technologists and reporters experimented with the use of UAVs inside of traditional newsrooms before the most recent summer 2016 legal, ethical, or normative guidance from either their institutions or government regulators. From an early adoption of technology perspective, these early adopters are disruptive innovators. By early adopters, we refer to individuals who use UAVs before others or before the use of the technology becomes institutionalized in newsrooms and journalism practice.

\section{Disruptive Innovation Theory}

While disruption has become a buzzword in the corporate world, the theory that underlies it applies to early drone use cases in journalism. Developed by Joseph L. Bower and Clay Christensen (1995), disruption theory suggests that while established companies are good at developing technologies and practices that serve their existing customer base, they are limited by the worldview, norms, and regulatory frameworks that made them successful. These incumbent forces lead to a more conservative risk calculus that leaves a space for innovation and the development of niche communities of practice to emerge on the edges of established markets. Once a disruptive technology is established on the margins, the technology can often scale to compete with incumbents (Christensen, Craig, and Hart 2001; Christensen, Raynor, and McDonald 2015). While this form of disruptive innovation generally occurs outside of established institutions, there are occasions of internal disruptions, whereby "a technology or product is inherently sustaining or disruptive" (Christensen, Raynor, and McDonald 2015).

As Christensen, Skok, and Allworth (2012) argue, the theory of disruptive innovation can be applied to journalism to explain the transition of legacy media organizations to the new practices and technologies emerging in the digital space. Legacy media organizations have deployed technologies that serve their existing audiences (either through increased reach, engagement, or monetization). Because of the strong incentives to serve existing, even if declining, customers, legacy media organizations have missed the opportunities afforded the emergence of new niche audiences (Christensen, Skok, and Allworth 2012). This has occurred both for niche topics or communities (such as politics, data journalism, sports, or justice reporting), and for the leveraging of new technologies and platforms (such as virtual reality or augmented reality, automation, and native advertising platforms) (Wessel 2016).

Astrid Gynnild (2014) argued that from the perspective of robot witnessing, UAVs represent a disruptive innovation. In this paper, we explore how UAVs are a disruptive innovation that started outside newsrooms and which are making their way into 
journalism. This research distinguishes itself by focusing on early adopters and examining their perspectives using interviews. In doing so, we start a discussion on how emerging technologies in newsrooms can be a disruptive innovation.

UAVs are an important case of a disruptive journalistic technology because their adoption and use were limited by established norms, institutional cultures, and laws. Yet, despite these limitations, a community of early adopters inside and outside legacy newsrooms experimented with this technology. We therefore sought out journalists who have used UAVs to better understand how these early adopters brought technologies and practices from the margins of journalism into established institutions. Two questions guided this research:

RQ1: Is this early adoption an example of a rare internal disruption?

RQ2: Did this early risk-taking lead to a wider institutionalization of journalistic uses of UAVs?

\section{From a Prescriptive to an Empirical Account of UAVs in Journalism}

The civilian use of drone technology has expanded rapidly with the availability of consumer UAVs and journalists have begun using small, UAVs vehicles to gather photos, video, and data (Waite 2014). Although scarce, scholarly accounts of journalistic uses of UAVs have mapped the ways that the technological affordances of UAVs can solve news production challenges such as access and provide tools for storytelling (Holton et al. 2015; Pavlik 2015). While scholars have explored journalistic uses of UAVs in terms of ethics, legality, and morality (Goldberg, Corcoran, and Picard 2013; Waite 2014), few have included journalistic perspectives or offered in-depth interviews with users.

Most of the moral, ethical, and legal literature is interpretive (Jarvis 2014; Syed and Berry 2014), tackling issues including surveillance and sousveillance (Clarke 2014; Tremayne and Clark 2014) as well as privacy and safety (Calo 2011; Chapa 2013; Culver 2014; Finn and Wright 2012; Kaminski 2013). For instance, Tremayne and Clark (2014) argued that UAVs extend the surveillance capabilities of media, allowing for something closer to sousveillance, or observation from below, and resulting in a "democratization of surveillance." Legal scholar Ryan Calo (2011) suggested that the journalistic use of UAVs is inevitable, given their low cost, availability, and safety features. According to Calo, privacy law will not likely stand in the way, and could actually represent the "visceral jolt" that society needs to bring current privacy laws into line with technological developments. Also, as Culver (2014) noted, journalistic usage of UAVs can lead to negative views of newsgathering among citizens who are already wary of surveillance technologies in other contexts. In response to potential negative views of newsgathering with UAVs, the Professional Society of Drone Journalists created a code of ethics for drone journalists. This code includes taking all possible measures to prevent collisions and accidents, and respect privacy, the law, and public space.

While most legal and ethical research on journalistic uses of UAVs focuses on what kind of ethical concerns or law might apply, a few studies have explored journalistic norms of practices. In a report for Columbia University's Tow Center for Digital Journalism, Fergus Pitt placed the emergence of UAV journalism in the context of wider 
experimentation with sensors (Pitt 2014). In a report for the Reuters Institute for the Study of Journalism at the University of Oxford, David Goldberg, Mark Corcoran, and Robert G. Picard (2013) outlined a range of journalistic cases of UAV use. In a series of papers on the topic, Matt Waite documented his experimentation and study of UAV technology for journalism on his website, the Drone Journalism Lab (Waite 2016b). Also Rachel Finn and David Wright (2012) searched how a few journalists have expressed concerns about UAVs and the intrusion of civil liberties. The limited amount of empirical work on journalistic uses of UAVs is perhaps due to the journalists' fear of retribution from those who may claim they use UAVs in the US regulatory context.

Building on this literature, this paper explores a group of UAV early adopters in US journalism, what drew them to combine UAVs with journalism, and how journalistic uses of UAVs are challenging broader UAV practices. These perspectives of early professional adopters will allow scholars to understand how this technology is disruptive in the context of journalism and US law and regulation.

\section{Method}

In March 2015, we conducted 13 semi-structured interviews with early adopters who have used UAVs in news production. The sample is small and representative, since there is a well-knit community of early adopters who tend to know each other and have a clear picture of who was working with this technology. As a result, our sample possesses a high internal validity. To find early adopters, we first conducted an online search for individuals who have used UAVs in their reportage. We then used the snowball method to identify additional interviewees. Our aim was to interview people in diverse positions so that we could explore the ways early adopters used UAVs. Our sample consisted mostly of current and former freelancers, broadcasters, reporters, and editors. We conducted the interviews by telephone and Skype, which allowed interviewees to speak in an informal atmosphere (Novick 2008). The interviews lasted on average 40 minutes. We read and coded all of the interview transcripts. In a qualitative data analysis of 13 semi-open interviews, we read our empirical data and coded these notes into groupings of emergent themes. We anonymized the interviews at the request of most individuals we interviewed.

Semi-structured interviews reveal unforeseen and sometimes unexplored areas of research, and are useful for understanding an emerging technology such as UAVs. Interviews can also broaden the scope of previous studies and allow for flexibility and more casual conversations with respondents (Brennan, Kanayama, and Pope 2013). In studying emerging technologies and early adopters' uses of these technologies, semistructured interviews provide guidelines for the researcher to follow. In our interviews, we listened to each response, following up on important points while working to keep the respondent on track (Anderson 2012). We also followed up with questions a second or third time for accuracy and clarity (Kvale 2006). That way, we took a look into the world of the journalistic use of UAVs. Interview questions included: How have you used UAVs in your reporting? How did you start using UAVs? Can you discuss an instance when a colleague made effective use of a UAV? Our open-ended questions build on the existing literature on UAVs and journalism. 


\section{Disruption and Journalistic Uses of UAVs}

This section explores why and how these adopters started using UAVs, and if they found ways to work around organizational and institutional boundaries. This empirical section lays the ground for a discussion on how UAV early adopters have become norm entrepreneurs, "individuals who are in favor of changes in norms face a free rider problem" (Sunstein 1996, 23), and have enabled disruptive innovation within organizations.

\section{Disruptive Technologists and Hobbyists}

The UAV users we spoke to were not trained in photojournalism but are invested in technology. Some users even call themselves "technologists" rather than "journalists." As a result, the early adoption of UAVs operated outside of professional boundaries of journalism, more as a hobby, and was spearheaded by hobbyists and practitioners in universities (e.g. University of Missouri Drone Journalism Program and the Drone Journalism Lab at the University of Nebraska-Lincoln's College of Journalism and Mass Communications). Illustrating this trend, in an interview, one reporter mentioned that coming into UAV journalism, he did not call himself a journalist:

I call myself a journalism technologist in the sense that I don't, I was not a journalist first, then came into drones. It was more the other way around. In the sense that I'm, I don't see a story and then start doing that and they go "oh let's add a drone component" or ... I don't even so much ... The drone part is the focus. So in a way unless somebody else approaches me with a story where they see the value of the drone, most of the work that I have been doing has been sort of drone-centric in the sense that I'm trying to see can we take the drone into this environment and do something interesting and then have a story.

The reporter added that his focus on UAVs led the reporter to a few freelance projects:

People have been noticing that, and that's why we have been approached to collaborate and to contribute content ... Then in [month] I partnered up with a reporter from [news organization] to do a story about [topic]. This guy approached us, having seen the work that we'd been doing, and asked for us to help him out with that story.

Although most of the people we interviewed were either former reporters, stringers, or journalists working for a news organization, most of the people we interviewed came into UAV reporting for their love of the technology and the possibility of using UAVs for storytelling. As Matthew Powers $(2012,25)$ wrote, some types of work are "rooted in the affordance of technical capacities" that refers to "the journalistic nature of such work." These "technology-specific" forms of work include programmer journalist or graphic designer.

In our case, "technology-specific" forms of work refers to UAV journalists. In our interviews, journalistic usage of UAVs was the main form of newsgathering the reporters used. Therefore, early UAV journalism referred to a "technology-specific" type of work. The individuals we interviewed used the technology because of low costs, to provide better and more precise visualization for storytelling, and to have safe access to uncharted reporting terrains. 


\section{Change in Witnessing Perspectives}

In our interviews, reporters pointed to changes in storytelling, such as precision of image and providing a range of perspectives that other forms of photography did not allow. One photojournalist claimed that there were outdoor stories that can be told from the ground and from a unique perspective:

To bring in the aerial element, and not just any aerial element, but the perspective of the drone. To be able to go from skimming over the surface of [a place], skimming over [another place], to then swooping up high, to have that type of experiential component.

For example, that journalist started working with three-dimensional (3D) models by:

[C]reating, taking photographs from a drone and then creating a three-dimensional model out of those photographs, or creating a virtual environment that you can explore on your computer or your phone ... I applied those same imaging techniques, created a giant 3D model of the [place] so that you can now explore the [place], the [place] like a video game kind of. You can fly around and you can see where the [buildings] are at the corner of the [place] and the [other location], where people live.

For this journalist, the UAV was disruptive because it allowed them to add depth that reporters have difficulty conveying through images and video, airplanes or helicopters. The reporter added:

When I'm shooting video I'm kind of all over the place rotating raising and lowering the drone to get those sort of cinematic interesting movement effects ... When I'm doing the 3D modeling I'm flying back and forth like a lawn mower just going over an area, very careful about altitude and speed so that I can get the right image resolution and the quality that I want.

A pioneer in 3D models, working outside of a traditional newsroom as a freelancer, this reporter used 3D models by taking photographs from UAVs and then creating a 3D model out of those photographs or a virtual environment that users can explore on computers or phones.

In our interviews, a recurring theme was the ability of journalists to produce more precise images. "You can get a really detailed view of where things are leaking out into areas," said a journalist. One drone entrepreneur claimed that "you can get really great shots of lightning during the storm, or that kind of stuff that the photos and the videos would sell quite a lot." To illustrate this, another reporter told us how UAVs provide different perspectives:

It was a great opportunity to use my quadcopter for that just to get a different perspective to show an overall of what the [scene] looked like versus shooting something from the ground with my camera ... They sent me up there and I was there for maybe five days shooting video and interviewing people, going on [a place] and things like that. I took my quadcopter because I knew I wanted to get aerials of the areas where the [things] were and some really pretty visuals of the [place] where the [things] were.

In sum, as Goldberg, Corcoran, and Picard (2013) wrote, "the drone or UAV industry now chants the mantra of the three D's-'If the job is too dull, dirty, or dangerousget a UAV to do it."' In journalism, UAVs provide a disruptive innovation as they offer a way for journalists to develop new forms of witnessing news and access to remote 
locations, disaster areas, and other places that would have otherwise been inaccessible to the vast majority of journalists.

\section{Access}

Another reason for using UAVs was access. As Mike Ananny has written, reporters can "now tell stories, from farther away, and increasingly alongside audiences who describe feeling immersed in and affected by events that they once had to wait weeks to learn about" (Ananny 2015). While drones allow journalists to have cheaper access to aerial imagery, reporters claimed that UAVs gave them access to areas that they would not otherwise have access to in order to gather news. As a result, and according to Gynnild (2014), UAVs in journalism might: (1) reduce the news media industry's need for human risk taking, (2) replace or supplement news coverage on the ground with new kinds of aerial views as well as options for aerial close-ups, and (3) allow for the journalistic hunt for the visual conquering of formally unwatched realities supporting the ongoing transition from a norm-based mindset to a more innovative one among professional journalists.

Similar to Gynnild's account of UAVs in journalism, these are all features that we noticed in practice. A reporter said that UAVs were "about accessing places that you can't access on your feet. Access to me I think is the main reason. To see things that you can't get to on your feet." Another reporter claimed that by using UAV night vision:

You can put different lenses on there like infrared, so for example, if there was a building collapse and you wanted to see if there were stuck, you could use the vehicles to see where people are at that you wouldn't see, obviously, with just the normal eye.

To illustrate this claim, the reporter said:

I launched my quadcopter up in the air about maybe 300 feet and was shooting one frame every five seconds with my GoPro as it was in the air. I was just flying around the [place] shooting aerials of what the sub looked like. It just made sense. It was a great opportunity to use my quadcopter for that just to get a different perspective to show an overall of what the sub looked like versus shooting something from the ground with my camera.

Providing different perspectives and access were two of the major reasons early adopters (including UAV hobbyists and technologists) mentioned using UAVs. The quest for providing journalistic perspectives motivated these norm entrepreneurs to continue to use the technology in their reporting.

\section{Safety and Regulation}

Human safety is another reason why reporters decided to use UAVs. As Holton et al. $(2015,4)$ wrote, "UAVs can navigate into dangerous spaces, such as active volcanoes or tornado flattened neighborhoods that most journalists and other individuals could not safely approach." A reporter confided that he used UAVs because he felt that the technology is "very, very powerful in emergency situations, because [journalists] are 
able to get you a much better perspective, and are a lot safer." Journalists are able to remain safe by capturing and sharing content, as well as by using the drone at distance from potential danger. As an illustration, a journalist stated:

Where it gets interesting for me is can they be used for things like on-demand remote sensing? You could combine GPS and reasonably high-resolution photos to create ondemand maps of an area, particularly in disaster situations. You could map the path of a tornado in the matter of hours. You could map hurricane damage? Could you map wildfire spread ... Could you add multi-spectral cameras to the mix and start looking at things that aren't immediately apparent to the eye, like drought, plant stress, soil moisture stress? Could you look at environmental change? Sometimes environmental change, shifting water, things like that is not immediately visible to the eye.

The autonomous algorithmic control of UAVs offers a cost-efficient way to capture images and data such as with sensor-based UAV journalism. "Fixing different temperature sensors or whatever on a drone and flying it out. That to me in my experience while very cool, it's still in the very experimental stage, people are not using it for that," said a freelancer. The freelancer described how "we visited a [place] and we flew the drone over the [place] through the [debris] so you could see how managing a controlled [debris] actually works, from the sky." Yet, when operated, UAVs could also be harmful to people: "Strong wind gusts, radio interference, mechanical malfunction, and operator errors could bring down a UAV with potentially deadly force" (Holton et al. 2015, 4). While these early adopters experimenting with the technology are suggesting that UAVs are disrupting journalistic practices, we found that journalistic uses of UAVs bolstered existing journalistic practices outside traditional legacy newsrooms.

\section{Innovation Disruptors and Organizational Boundaries}

While UAV regulations for reporters are restrictive, the early adopters we spoke to found ways to work around organizational and institutional boundaries by (1) acting as citizen news witnesses or using citizen witnessing footage and (2) going international. With a budget of approximately $\$ 400$ for a DJ Phantom 3, the possibilities of journalists and other citizens increase the potential to produce acts of journalism using UAVs. UAVs push journalistic institutions to rethink journalistic witnessing.

In March 2014, Brian Wilson was the first to eyewitness a gas explosion in Harlem, New York, near the Metro North rail lines. Wilson asked the authorities to film, and launched his drone above the explosion zone. News organizations used part of his 30-minute footage to cover the news (Holton, Lawson, and Love 2015). According to early adopters we talked to, acting as citizen journalists was common practice.

Many reporters mentioned working or knowing other reporters working "off the clock" or using citizen material of UAVs. To go around the restrictive regulation, whether assumed or real, some reporters worked "off the clock." A reporter confided:

I could do it on my own time so I would listen to a scanner and check the news for breaking news. Anything that was worthy of an aerial perspective, I would go and take video and pictures of. That included car accidents, fires, and gun standoff situations.

Similarly, another reporter said that using UAVs take a lot of practice: 
I bought it and I spent time practicing ... Of course, by the time I got good at flying it and comfortable, the diving season was over so I really couldn't fly it for the purpose I got it for, which was to shoot aerials over the boat as the divers were going in. I started using it for work for different daily assignments on certain things and for a couple of stories I was working on.

Others used citizen news witnessing. For example, one reporter mentioned that a print journalist filmed [a scene of nature] on a Sunday with a UAV. The reporter came in the newsroom the following Monday and published the video online. S/he continued:

[The reporter] tried to say that because he shot it on a Saturday on his own time that it was somehow okay because he wasn't on the clock for the company. I might have to strain my brain a little bit more here, but that's the only print organization that I know of that has done something like that. Most of the ones that l've heard have been broadcasting entities and mostly it's working with production crews that end up getting hired by broadcast entities to go out and do something. It's not the news organizations themselves.

Also a few decided not to take chances by using UAVs in the United States. Rather, they traveled to use UAVs:

We had a lot of discussion about whether it would be okay to fly in someone else's property. That was not made entirely clear in the circular. We talked to lawyers. We decided not to. We did all of our stories on public lands, federal parks, and that kind of thing but that was a very restrictive thing. That meant basically all stories, all urban stories were off the table. Any stories that required filming people, like filming going over people's heads, that was off the table. That really takes out a large number of stories you could do.

Reflecting on another news organization, a practitioner claimed: "Their [news organization] general counsels have been pretty adamant that their people can't be doing anything in the US. So the stuff that you have seen on [news organization] has been immediately across the border in Canada." In our interviews, a small number of reporters did not want to take the legal risk in the United States and decided to use drones in places outside of the United States, where regulations were more flexible.

While some reporters stopped using UAVs when faced with restrictive regulations or traveled to countries where it was legal to use the technology, there was considerable experimentation on the part of these early adopters. To curtail the restrictions they faced, some reporters worked off the clock or used citizen witness footage. This has important implications on the nature of UAV footage in the news. Established institutions in the United States fostered these creative solutions to the limitations on drone use, leading to the embedding of amateur footage inside the journalism of legacy institutions. Yet, as disruption theory suggests, it is unclear whether the new technology will render previous forms of journalistic witnessing obsolete. From the perspectives of reporters we interviewed, UAVs provide a way to witness differently than say a helicopter. UAVs also democratize witnessing "in the air;" and limit the risk associated with access and covering dangerous areas. 


\section{Law, Regulation, and a Disruptive Innovation: The Rise of Norm Entrepreneurs}

In our interviews, we noticed that, over time, some reporters were shying away from institutional regulation either by working "off the clock," going on their own using UAVs as a hobbyist innovation, or going international in places where it was legally possible to use the technology.

Historically, innovation in news production has often occurred outside traditional newsrooms' settings and, in many cases, led to the creation of new forms of journalism (e.g. photojournalism and the rise of photojournalism magazines). Along those lines, Adrienne Russells (2011) argues that much of the innovation happening in newsrooms takes place outside newsrooms (see also Holton 2016). Similarly, Steve Myers (2011) highlights a tension between news cycle and innovation, suggesting that a lot of innovation happened outside the daily cycle of more traditionally inclined newsrooms, mainly because of the constraints of the news cycle (e.g. many radio shows are hosted once a week while reporters need to blog off the working clock).

In the literature on disruptive innovation, this innovation process would be seen as a vulnerability for legacy organizations, leaving them open to the emergence of competition which, having secured a niche audience, could grow into a threat for market share. But this is not what has happened with the use of UAVs in journalism. Instead, as we see above, norm entrepreneurs, mostly inside legacy organizations, remained flexible enough despite the regulatory, legal, and cultural constraints to lay the foundation for a more professionalized practice once these constraints were loosened. It is important to note that in interviews, a few early adopters told us that they noticed instances of UAV use in weather or traffic broadcasts, although broadcast organizations would not acknowledge the shots were done with UAVs.

In sum, the ethics of UAV journalism have been mostly debated and articulated outside of newsrooms (such as by the Professional Society of Drone Journalists). UAV journalistic ethics emerged within an enthusiast rather than a newsroom setting, likely due to the challenges in publicly discussing a practice that pushed legal boundaries. As Sunstein $(1996,46)$ wrote, "norms can be far more fragile than they appear; hence norm entrepreneurs can help solve collective action problems and 'norm bandwagons' are common."

\section{Discussion}

This research is based on interviews with early adopters of UAVs in journalism. We conducted these interviews in early 2015, at a time when the FAA heavily regulated journalistic uses of UAVs. This paper explored how these UAV users sought to bring the technology and associated practices into news organizations and journalism.

As Christensen, Raynor, and McDonald (2015) wrote: "incumbents' focus on their existing customers becomes institutionalized in internal processes that make it difficult for even senior managers to shift investment to disruptive innovations." However, our interviews show that despite these limitations, there was a subset of norm entrepreneurs inside traditional news organizations that were willing to push the bounds or institutional constraints to experiment with the use of drones. This allowed for a form 
of internal disruption that enabled news organizations to be prepared for the normalization of drone use that came through the release of Federal regulations, thereby stemming off more substantial external disruption.

We found that journalistic uses of UAVs occurred mainly from the margins of legacy journalistic organizations with hopes from these users that it would become embedded into the established news institutions. Reporters who use UAVs for news production are an example of what Christensen (2013) argues is a disruption (see also Gynnild 2014). This means that individuals inside newsrooms who did not necessarily identify as journalists were given the freedom to experiment with an emerging technology on the bounds of acceptable practice. This laid the ground for a more diverse and professionalized set of practices once these constraints were lifted.

At this point in the early history of UAVs in journalism, there is little evidence on how the early risk of using UAVs led to the wider normalization of UAV uses in journalism. However, there are more and more UAVs in institutions such as US universities. We can also notice seeds of this institutionalization, notably on August 12-14, 2016, when the Drone Journalism Lab led by Matt Waite held a "drone boot camp" that sought to explore practices and regulation in UAV journalism.

As with the case of UAVs in journalism, and as Bower and Christensen (1995) pointed out, industry leaders are rarely the first to commercialize new technologies that do not initially meet mainstream customers' demands or can appeal to small or emerging markets:

To remain at the top of their industries, managers must first be able to spot the technologies that fall into this category. To pursue these technologies, managers must protect them from the processes and incentives that are geared to serving mainstream customers. And the only way to do that is to create organizations that are completely independent of the mainstream business. (Bower and Christensen 1995)

Norm entrepreneurs in UAV journalism are thus innovators operating from the outskirts of news organizations. They offer the possibility for mainstream legacy media organizations to institutionalize a disruptive innovation, creating a whole new market for journalism and journalistic witnessing (whether it relates to journalistic norms, practices, or emerging journalistic responsibilities or beats).

As UAVs are introduced into newsrooms and journalistic practice, it would be relevant to monitor how this technology will be sustained in the long term in the United States, and how usage differs in different socio-legal contexts. UAVs could be dethroned by a new disruptive technology and/or cohabit with other disruptive technologies (e.g. virtual reality or Web-based metrics). While the literature on UAV journalism addresses how the legal and ethical aspects of the technology may impair newsgathering with the technology (Calo 2011), little empirical research has addressed how journalists have experimented with the technology.

We argue that legal and regulatory restraints placed on the use of UAVs facilitated the emergence of a new form of norm entrepreneurs inside journalistic institutions. These individuals were able to experiment on the fringes of acceptable practice. Journalists seeded their organizations with the skill set and institutional capacity to engage constructively with the use of UAVs once constraints were lifted. In the language of Bower and Christensen (1995), this protected them from outside disruptive innovation. 
Going forward, more explorations of how and why reporters used this technology are needed. Further studies on the impact of these uses in the development of a technological innovation in newsrooms would also be useful. Other technologies, such as virtual reality, augmented reality, or data journalism, present similar challenges for journalists, though without the same degree of legal limitation as UAVs. Further research should address how scholars and practitioners can connect the concept of disruptive innovation and norm entrepreneurs to other emerging technologies in journalism, and how institutions adapt to new spaces of professional practice that do not fit comfortably within their norms, cultures, and skill sets.

\section{DISCLOSURE STATEMENT}

No potential conflict of interest was reported by the authors.

\section{REFERENCES}

Anderson, Claire. 2012. "Presenting and Evaluating Qualitative Research." American Journal of Pharmaceutical Education 74 (8): 141.

Ananny, Mike. 2015. "Creating Proper Distance Through Networked Infrastructure: Examining Google Glass for Evidence of Moral, Journalistic Witnessing." In Boundaries of Journalism: Professionalism, Practices, Participation, edited by Matt Carlson and Seth C. Lewis, New York: Routledge.

Bower, Joseph L., and Clay Christensen. 1995. "Disruptive Technologies: Catching the Wave." Harvard Business Review, December. https://hbr.org/2015/12/what-is-disruptive-innova tion

Brennan, Brian P., Gen Kanayama, and Harrison G. Pope. 2013. "Performance-Enhancing Drugs on the Web: A Growing Public-Health Issue." The American Journal on Addictions 22 (2): 158-161.

Calo, Ryan. 2011. "The Drone as Privacy Catalyst."Stanford Law Review Online, December. http://www.stanfordlawreview.org/online/drone-privacy-catalyst

Chapa, Lilly. 2013. "Drone Journalism Begins Slow Take Off: Ethical, Legal Issues Abound as Drones Contemplated for Newsgathering." The News Media \& The Law 9-13.

Christensen, Clayton. 2013. "The Innovator's Dilemma: When New Technologies Cause Great Firms to Fail." Harvard Business Review, November. https://hbr.org/product/the-innova tor-s-dilemma-when-new-technologies-cause-great-firms-to-fail/1196XE-KND-ENG

Christensen, Clayton, T. Craig, and S. Hart 2001. The Great Disruption. Foreign Affairs, March/ April. https://www.foreignaffairs.com/articles/united-states/2001-03-01/great-disruption

Christensen, Clayton, David Skok, and James Allworth. 2012. "Breaking News: Mastering the Art of Disruptive Innovation in Journalism." Nieman Reports, September 15. http://nie manreports.org/articles/breaking-news

Christensen, Clayton, Michael E. Raynor, and Rory McDonald. 2015. "What is Disruptive Innovation?" Harvard Business Review, December. https://hbr.org/2015/12/what-is-disrup tive-innovation

Clarke, Roger. 2014. "The Regulation of the Impact of Civilian Drones on Behavioral Privacy." Computer Law \& Society Review 30 (3): 286-305. 
Culver, Kathleen. 2014. "From Battlefield to Newsroom: Ethical Implications of Drone Technology in Journalism." Journal of Mass Media Ethics: Exploring Questions of Media Morality 29 (1): 52-64.

Finn, Rachel, and David Wright. 2012. "Unmanned Aircraft Systems: Surveillance, Ethics and Privacy in Civil Applications." Computer Law \& Society Review 28 (2): 184-194.

Goldberg, David, Mark Corcoran, and Robert G. Picard. 2013. Remotely Piloted Aircraft Systems \& Journalism: Opportunities and Challenges of Drones in News Gathering." Oxford, UK: Reuters Institute for the Study of Journalism. http://reutersinstitute.politics.ox.ac.uk/ publication/remotely-piloted-aircraft-systems-and-journalism

Gynnild, Astrid. 2014. "The Robot Eye Witness." Digital Journalism 2 (3): 334-343.

Holton, Avery E. 2016. "Intrapreneurial Informants: An Emergent Role of Freelance Journalists." Journalism Practice 10 (7): 917-927.

Holton, Avery E., Sean Lawson, and Cynthia D. Love. 2015. "Unmanned Aerial Vehicles." Journalism Practice 9 (5): 634-650.

Jarvis, John. 2014. "The Ethical Debate of Drone Journalism: Flying Into the Future of Reporting." Research Paper 475.

Kaminski, Margot. 2013. "Drone Federalism: Civilian Drones and the Things They Carry." California Law Review 8 : 57-74.

Kvale, Steinar. 2006. "Dominance Through Interviews and Dialogue." Qualitative Inquiry 12 (3): 480-500.

Myers, Steven. 2011. "Key Departures Suggest 4 Factors Critical to the Future of Programming and Journalism." Poynter, February 17. http://www.poynter.org/2011/key-depar tures-point-to-4-factors-critical-to-the-future-of-programming-and-journalism/119853

Novick, Gina. 2008. "Is There a Bias Against Telephone Interviews in Qualitative Research?" Research in Nursing and Health 31 (4): 391-398.

Pavlik, John. 2015. "Transformation: Examining the Implications of Emerging Technology for Journalism, Media and Society." Athens Journal of Mass Media and Communications 1 (1): 1-16.

Pitt, Fergus. 2014. Sensors and journalism. Tow Center for Digital Journalism. http://towcen ter.org/research/sensors-and-journalism/

Powers, Matthew. 2012. "'In Forms That are Familiar and Yet-to-Be Invented': American Journalism and the Discourse of Technologically Specific Work." Journal of Communication Inquiry 36 (1): 24-43.

Russells, Adrienne. 2011. Networked: A Contemporary History of News in Transition. Cambridge, UK: Polity Press.

Sunstein, Cass. 1996. "Social Norms and Social Roles." Columbia Law Review 96 (903): 1-47.

Syed, Nabiha, and Michael Berry. 2014. "Journo-Drones: A Flight over the Legal Landscape." Communications Lawyer $30 \quad$ (3): 1-10. http://www.lskslaw.com/documents/ CL_Jun14_v30n4_SyedBerry.pdf.

Tremayne, Mark, and Andrew Clark. 2014. “New Perspectives from the Sky: Unmanned Aerial Vehicles and Journalism." Digital Journalism 2 (2): 232-246.

Waite, Matt. 2014. "Journalism with Flying Robots." XRDS 20 (3): 28-31.

Waite, Matt. 2016. "In 60 Days, Drone Journalism will be Legally Possible in any US Newsroom." Neiman Journalism Lab, June 21. http://www.niemanlab.org/2016/06/in-60days-drone-journalism-will-be-legally-possible-in-any-u-s-newsroom

Waite, Matt, 2016. "Drone Journalism Lab." September 14. http://www.dronejournalismlab. org 
Wessel, Maxwell. 2016. "How Big Data is Changing Disruptive Innovation." Harvard Business Review, January 27. https://hbr.org/2016/01/how-big-data-is-changing-disruptive-inno vation

Valerie Belair-Gagnon (author to whom correspondence should be addressed), School of Journalism and Mass Communication, University of Minnesota, USA. E-mail: vbg@umn.edu. (iD http://orcid.org/0000-0002-7756-1688

Taylor Owen, School of Journalism, University of British Columbia, Canada. E-mail: taylor.owen@gmail.com.

Avery E. Holton, Department of Communication, The University of Utah, USA. E-mail: avery.holton@gmail.com. (iD http://orcid.org/0000-0003-1307-2890. 